Supporting Information

\title{
Stainless Steel Mesh-supported NiS Nanosheet Array as Highly Efficient Catalyst for Oxygen Evolution Reaction
}

Jun Song Chen ${ }^{a b^{*}}$, Jiawen Ren ${ }^{a c}$, Menny Shalom ${ }^{a}$, Tim Fellinger ${ }^{a}$ and Markus Antonietti ${ }^{a}$

a Max-Planck-Institute of Colloids and Interfaces, Department of Colloid Chemistry, Am Mühlenberg 1, 14476 Potsdam-Golm, Germany.

${ }^{b}$ Department of Materials Science and Engineering, National University of Singapore, Singapore 117574.

${ }^{c}$ Exploration Hall, 20101 Academic Way, George Washington University, Ashburn, Virginia, United States. Zip code: 20147.

*To whom the correspondence should be addressed. Email: jschen002@gmail.com.

Table S1. EDX comparing the atomic percent (at\%) of different element for samples after different treatments.

\begin{tabular}{cccccccc} 
& Cr & Fe & Mn & Mo & Si & Ni & S \\
\hline SLS & 33.36 & 42.16 & 1.75 & 2.67 & 2.35 & 17.72 & - \\
SLS Treated with only TAA & 34.12 & 42.87 & 1.41 & 2.12 & 1.55 & 17.92 & - \\
NiS@SLS & 7.1 & 7.86 & 0.44 & 0.1 & 0.51 & 38.49 & 45.5 \\
\hline $\begin{array}{c}\text { NiS@SLS after 10-h } \\
\text { Chronoamperometry test }\end{array}$ & 15.44 & 17.99 & 0.56 & 1.2 & 1.04 & 48.43 & 15.33 \\
\hline
\end{tabular}




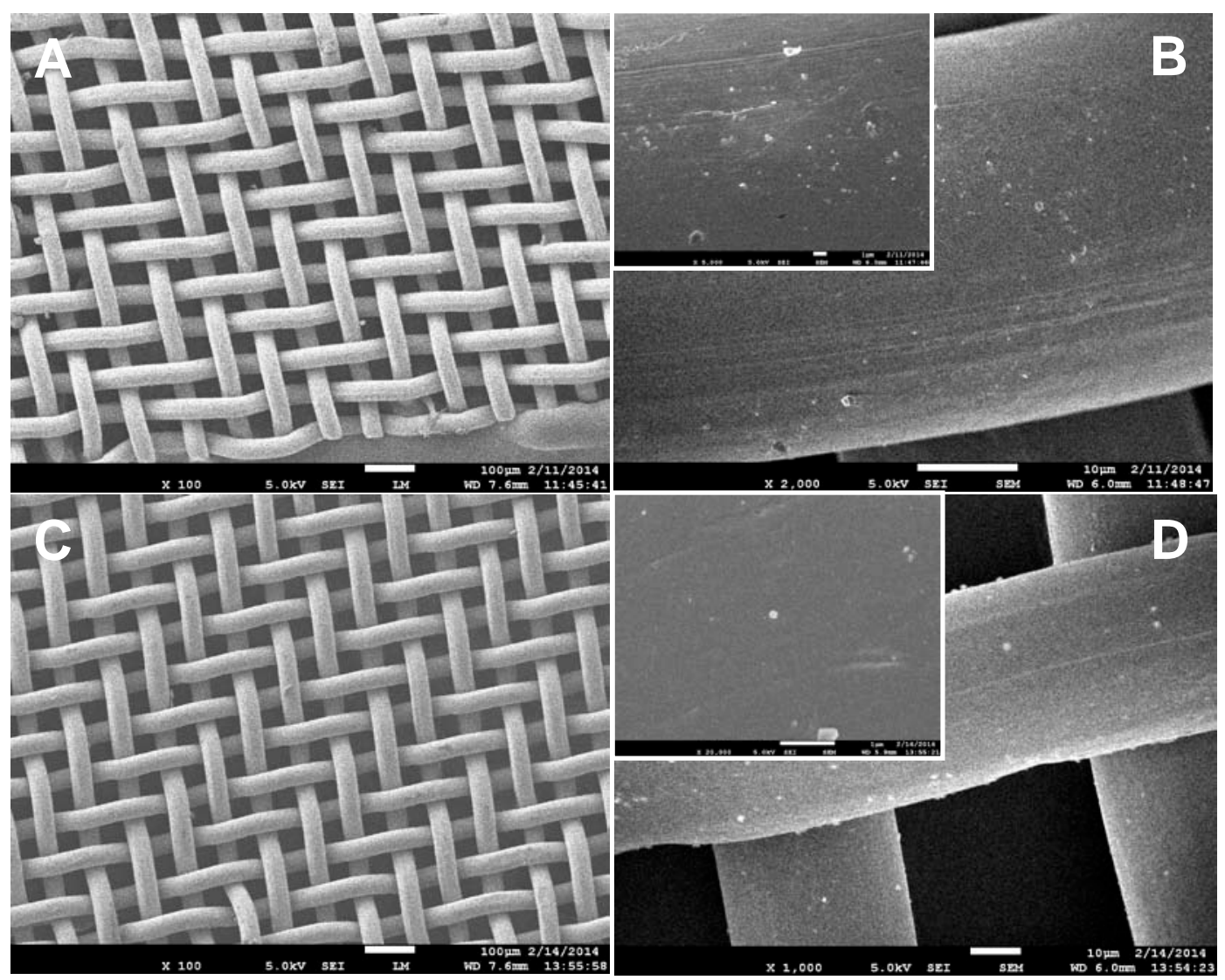

Figure S1. SEM images of pristine SLS (A-B) and SLS treated with only TAA (C-D).

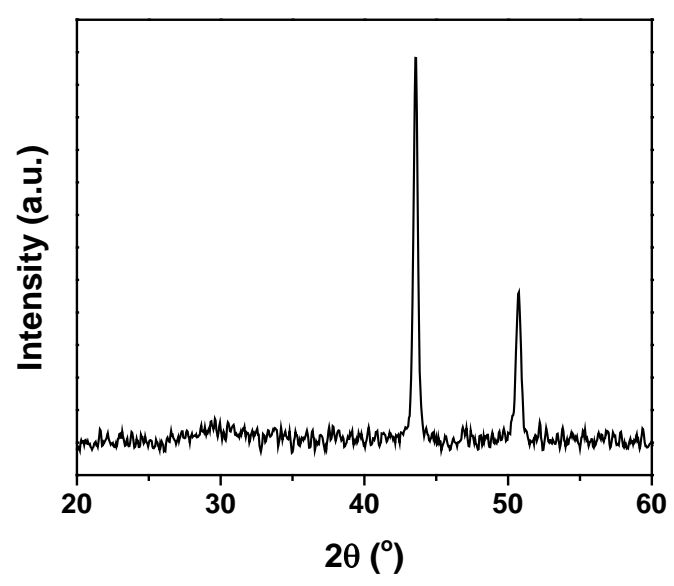

Figure S2. XRD of SLS treated with only TAA. 


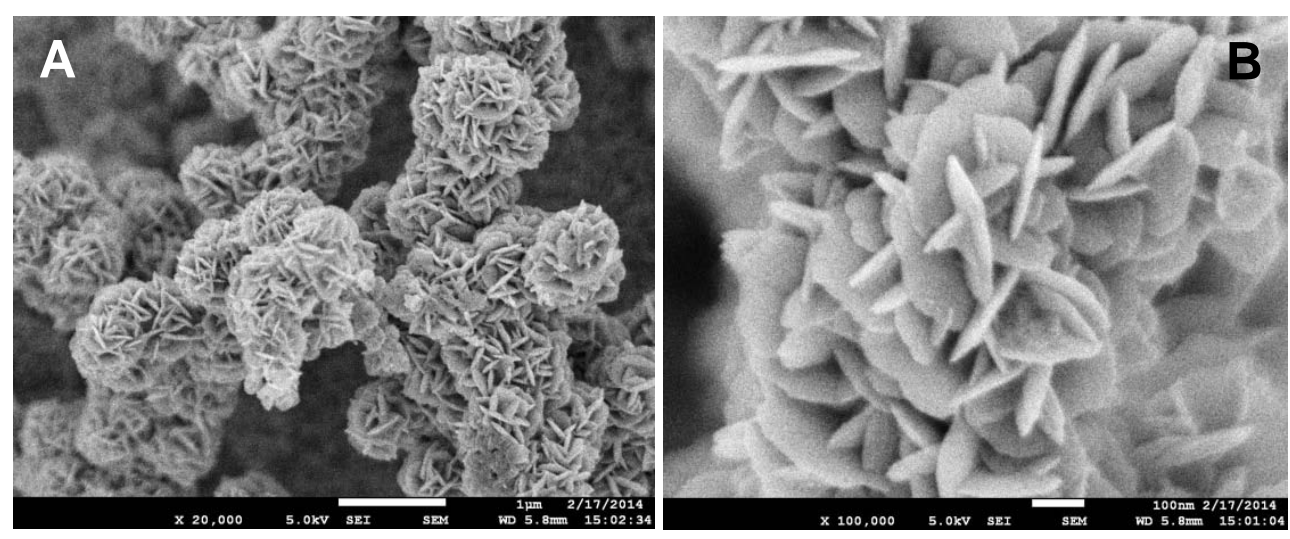

Figure S3. SEM images (A-B) of NiS synthesized without SLS substrate at different magnifications.
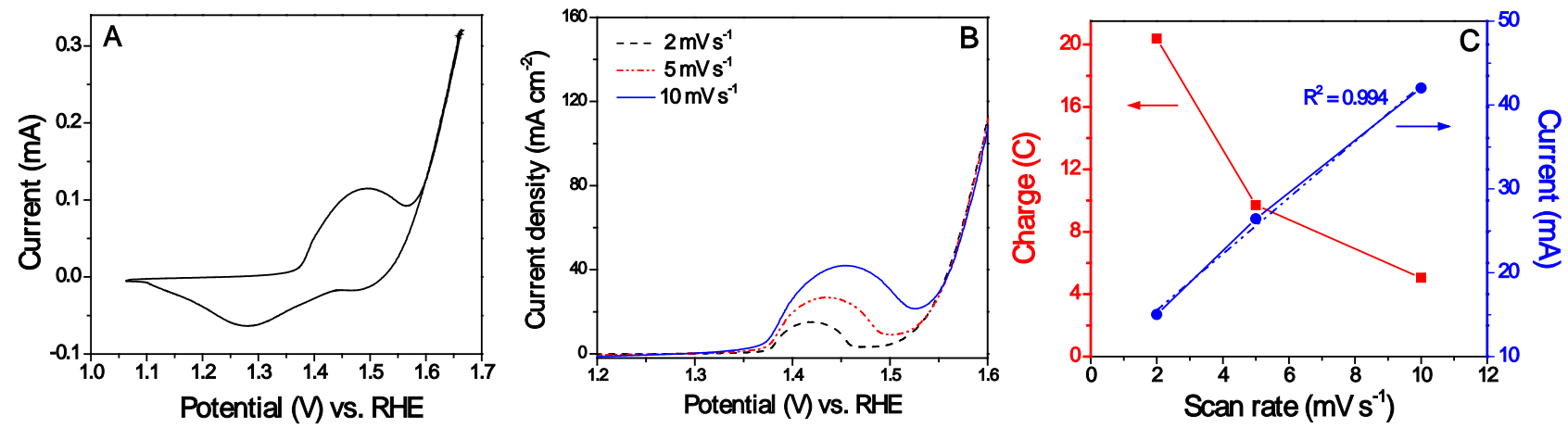

Figure S4. (A) CV profile of NiS@SLS at a scan rate of $25 \mathrm{mV} \mathrm{s}^{-1}$; (B) Polarization curves of NiS@SLS at different scan rates; (C) dependence of charge and peak current on scan rate derived from $B$. The dotted line in $C$ shows the fitted result of current vs. scan rate. 

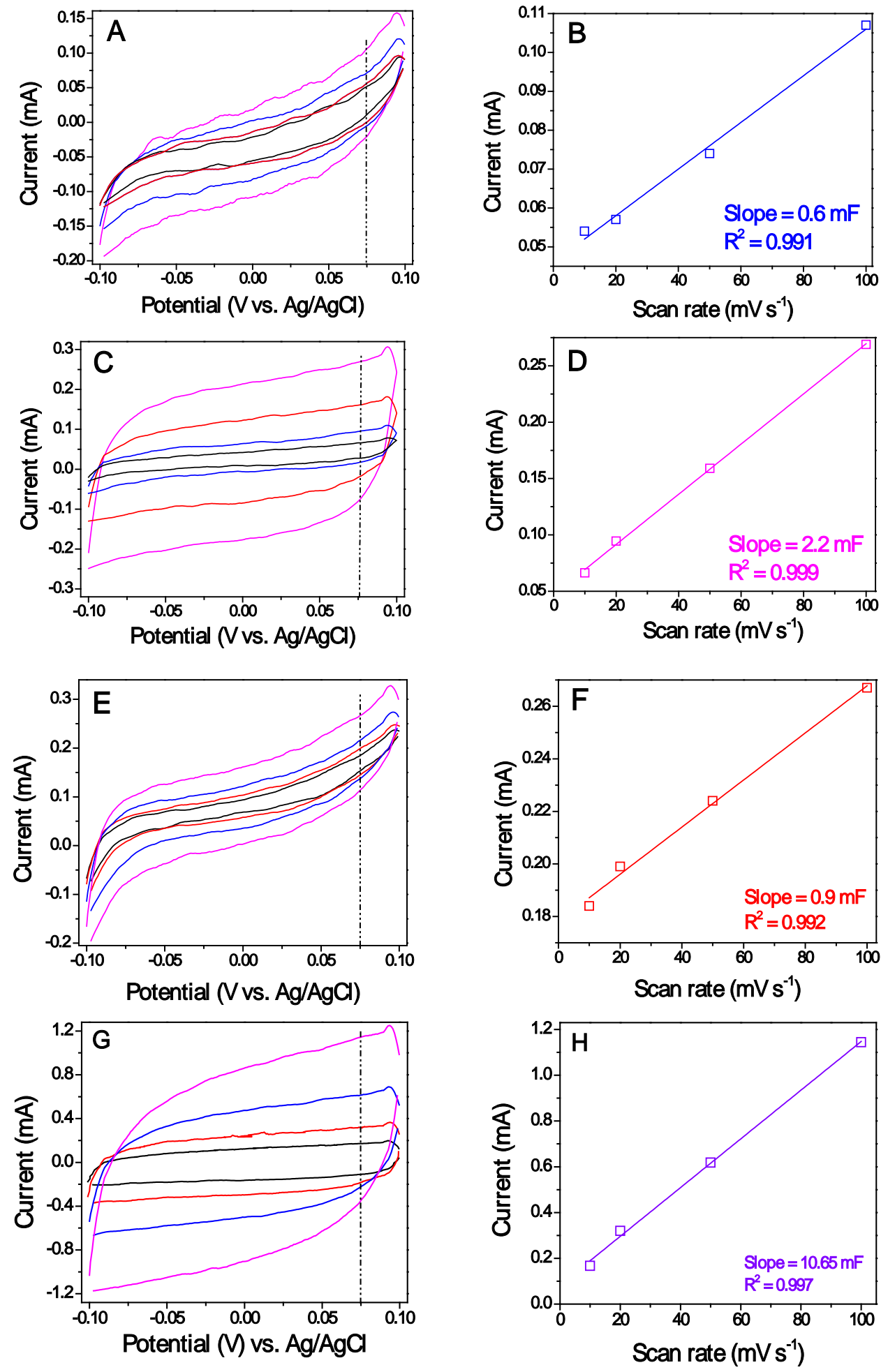

Figure S5. Cyclic voltammograms obtatined at non-faradaic potential region between $0.1 \mathrm{~V}$ and -0.1 V (vs. Ag/AgCl) (i.e., 1.064 V and 0.864 V vs. RHE) and of different samples: NiS@SLS (A), Pt/C on SLS (C), NiS on SLS (E) and $\mathrm{Ni}_{3} \mathrm{~S}_{2} @ \mathrm{Ni}(\mathrm{G})$ at different scan rates: $10 \mathrm{mV} \mathrm{s}^{-1}$ (black line), $20 \mathrm{mV}$ $\mathrm{s}^{-1}$ (red line), $50 \mathrm{mV} \mathrm{s}^{-1}$ (blue line), and $100 \mathrm{mV} \mathrm{s}^{-1}$ (pink line). The anodic currents measured at 75 $\mathrm{mV}$ (anodic sweep, marked by the dotted line) were plotted against scan rates of the corresponding sample (B, D, F and H). 


\section{Detailed calculation of EASA, $\boldsymbol{j}_{\mathrm{g}}$, and $\boldsymbol{j}_{\mathrm{s}}$}

The electrochemically active surface area (EASA) of the sample was estimated from the electrochemical double-layer capacitance $\left(\mathrm{C}_{\mathrm{DL}}\right)$ of the catalyst. ${ }^{1}$ The $\mathrm{C}_{\mathrm{DL}}$ was measured via cyclic voltammograms (CVs) with a potential range where no apparent Faradaic process was taking place. The double-layer charging current $i_{\mathrm{c}}$ can be related to the scan rates $v$ through the following equation: ${ }^{1}$

$i_{\mathrm{C}}=\mathrm{C}_{\mathrm{DL}} \times v$

Thus, plotting the charging currents at a specific potential against various scan rates leads to a straight line with the slope equal to $\mathrm{C}_{\mathrm{DL}}$ (Figure S5). Subsequently, the EASA can be obtained by the following equation: ${ }^{1}$

$\mathrm{EASA}=\mathrm{C}_{\mathrm{DL}} \div \mathrm{C}_{\mathrm{s}}$

where $\mathrm{C}_{\mathrm{s}}$ is the capacitance measured from ideally smooth, planar surfaces of catalysts, and here we use the typical value for $\mathrm{Ni}$ of $0.040 \mathrm{mF} \mathrm{cm}^{-2}$ for calculation. ${ }^{1}$ The roughness factor (RF) can then be calculated by dividing the EASA by the geometric area of the catalyst. We can therefore obtain the specific current density per catalyst surface area $j_{\mathrm{s}}$ by diving the current density per geometric area, $j_{\mathrm{g}}$, at a given overpotential by RF: ${ }^{1}$

$j_{\mathrm{s}}=j_{\mathrm{g}} \div \mathrm{RF}$

By following the above procedures and we selected the $j_{\mathrm{g}}$ value at the overpotential $\eta=297 \mathrm{mV}$, the $j_{\mathrm{s}}$ values of the samples can be finally calculated to be $\sim 1 \mathrm{~mA} \cdot \mathrm{cm}^{-2}$ for NiS@SLS, $0.018 \mathrm{~mA} \cdot \mathrm{cm}^{-2}$ for Pt/C on SLS, $0.089 \mathrm{~mA} \cdot \mathrm{cm}^{-2}$ for NiS on SLS, $0.01 \mathrm{~mA} \cdot \mathrm{cm}^{-2}$ for $\mathrm{Ni}_{3} \mathrm{~S}_{2} @ \mathrm{Ni}$, and $0.097 \mathrm{~mA} \cdot \mathrm{cm}^{-2}$ for SLS. Apparently, the as-prepared NiS@SLS sample demonstrates much higher $j_{\mathrm{s}}$ compared to other samples. 
Table S2. Fitted equivalent circuit elements of different samples.

\begin{tabular}{|c|c|c|c|c|c|c|c|c|}
\hline \multirow{2}{*}{$\begin{array}{c}\text { Rs } \\
\left(\Omega \cdot \mathrm{cm}^{-2}\right)\end{array}$} & \multirow{2}{*}{$\begin{array}{c}\mathbf{R}_{\mathrm{F}} \\
\left(\Omega \cdot \mathrm{cm}^{-2}\right)\end{array}$} & \multicolumn{2}{|l|}{$\mathrm{QPE}_{\mathrm{DL}}$} & \multirow{2}{*}{$\begin{array}{c}R_{\mathrm{CT}} \\
\left(\Omega \cdot \mathrm{cm}^{-2}\right)\end{array}$} & \multicolumn{2}{|c|}{$\mathbf{W}_{\mathrm{s}}$} & \multicolumn{2}{|l|}{$\mathrm{QPE}_{\mathrm{CT}}$} \\
\hline & & Q2 $\left(F \cdot \mathrm{cm}^{-2} \cdot \mathrm{s}^{\mathrm{n}-1}\right)$ & n2 & & W-R $\left(\Omega \cdot \mathrm{cm}^{-2}\right)$ & W-T (s) & Q1 $\left(F \cdot \mathrm{cm}^{-2} \cdot \mathrm{s}^{\mathrm{n}-1}\right)$ & n1 \\
\hline 8.03 & 0.64 & 0.67 & 0.85 & 0.08 & 1.32 & 1.93 & 0.013 & 0.85 \\
\hline 3.4 & 0.14 & $1.70 \mathrm{E}-04$ & 0.85 & 0.54 & 1.23 & $3.20 \mathrm{E}-03$ & $6.20 \mathrm{E}-04$ & 0.85 \\
\hline 8 & 0.61 & 0.52 & 0.85 & 2.07 & 0.12 & 5.88 & 0.0069 & 0.7 \\
\hline 9.7 & 0.43 & $1.20 \mathrm{E}-04$ & 0.85 & 1.77 & 2.81 & 0.015 & 5.30E-04 & 0.85 \\
\hline
\end{tabular}

Table S3. Comparison of OER activities of different Ni-based and the state-of-the-art $\mathrm{IrO}_{2}, \mathrm{RuO}_{2}$ catalysts.

\begin{tabular}{|c|c|c|c|c|}
\hline Name of Catalyst & Form of Catalyst & $\begin{array}{l}\text { Potential (V) vs. RHE at } \\
\quad j_{\mathrm{g}}=10 \mathrm{~mA} \cdot \mathrm{cm}^{-2}\end{array}$ & $\begin{array}{l}\text { Tafel slope } \\
\left(\mathrm{mV} \cdot \mathrm{dec}^{-1}\right)\end{array}$ & Reference \\
\hline NiS & nanosheets on SLS mesh & 1.524 & 47 & this work \\
\hline $\mathrm{Ni}$ & anodized on $\mathrm{Ni}$ foam & 1.764 & - & 2 \\
\hline $\mathrm{Ni}$ & nanoparticle on graphene & 1.587 & 188.6 & 3 \\
\hline $\mathrm{Ni}_{3} \mathrm{~S}_{2}$ & nanorod on Ni foam & 1.414 & 159.3 & 4 \\
\hline $\mathrm{NiCoS}_{4}$ & nanoparticle on rGO & 1.697 & - & 5 \\
\hline $\mathrm{NiCO}$ & nanosheets on rGO & 1.314 & 514 & 6 \\
\hline $\mathrm{Ni}-\mathrm{Fe}$ & thin film & 1.507 & 55 & 7 \\
\hline $\mathrm{NiOH}$ & thin film & 1.647 & - & 8 \\
\hline $\mathrm{NiO}$ & thin film & 1.628 & 72 & 9 \\
\hline $\mathrm{NiCO}_{2} \mathrm{O}_{4}$ & spinel nanowire & 1.639 & 95.9 & 10 \\
\hline $\mathrm{Ni} / \mathrm{Fe}(\mathrm{OH})_{2}$ & thin film & 1.448 & 33 & 11 \\
\hline $\mathrm{NiO}_{x}$ & \multirow{7}{*}{$\begin{array}{l}\text { electrodeposited on different } \\
\text { substrates }\end{array}$} & 1.643 & \multirow{7}{*}{ - } & \multirow{7}{*}{1} \\
\hline $\mathrm{NiCeO}_{x}$ & & 1.653 & & \\
\hline $\mathrm{NiCoO}_{x}$ & & 1.603 & & \\
\hline $\mathrm{NiCuO}_{x}$ & & 1.633 & & \\
\hline $\mathrm{NiFeO}_{x}$ & & 1.573 & & \\
\hline $\mathrm{NiLaO}_{x}$ & & 1.633 & & \\
\hline $\mathrm{IrO}_{2}$ & & 1.548 & & \\
\hline $\mathrm{IrO}_{2}$ & \multirow{3}{*}{ Commercial product } & 1.59 & 67 & \multirow[t]{2}{*}{12} \\
\hline \multirow{2}{*}{$\mathrm{RuO}_{2}$} & & 1.64 & 89 & \\
\hline & & 1.62 & - & 13 \\
\hline
\end{tabular}



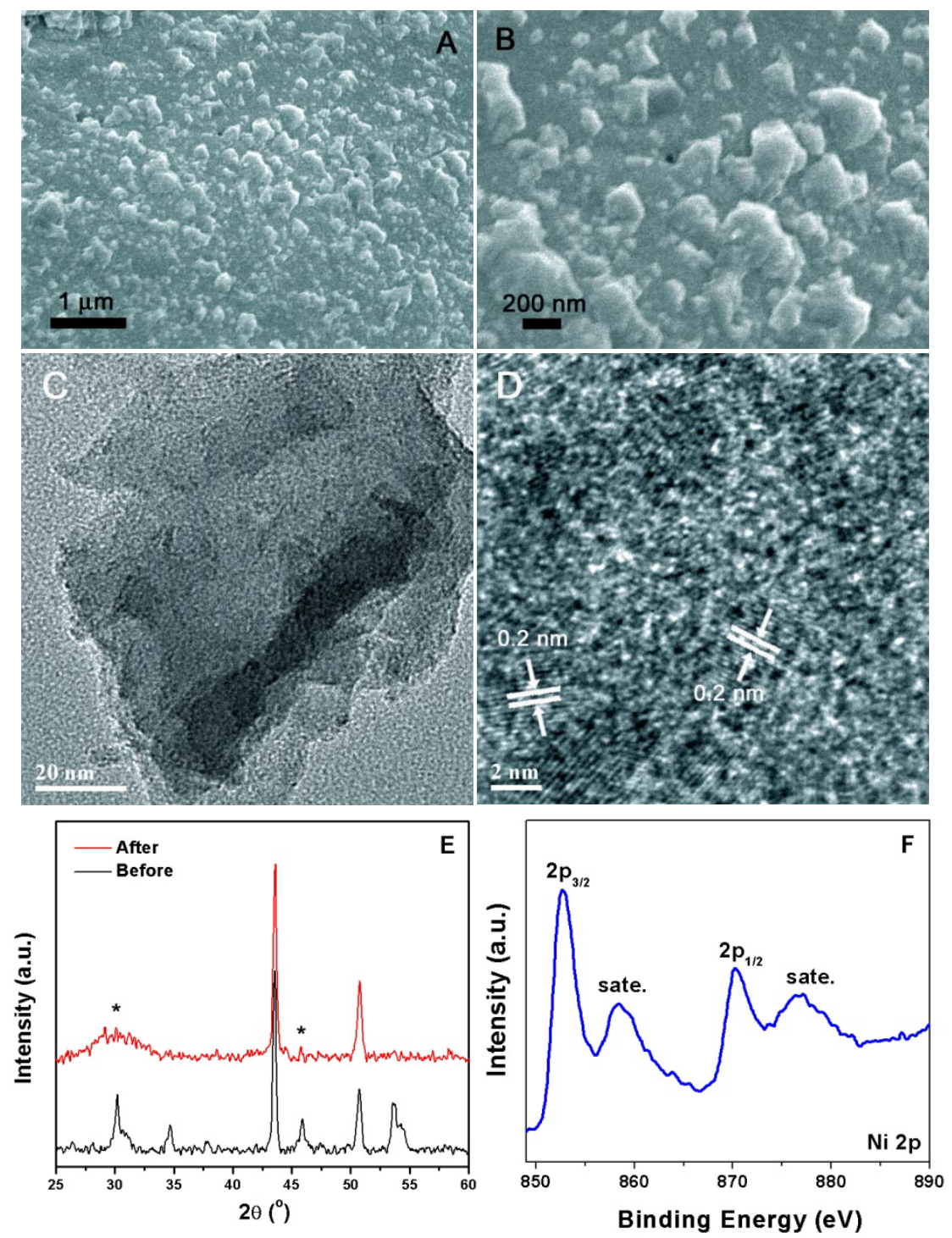

Figure S6. Post-mortem analysis of NiS@SLS after the 10-h chronoamperometry test: SEM (A-B), TEM (C) and HRTEM (D) images, XRD pattern (E) and XPS spectrum of Ni 2p (F). The asterisks in $\mathrm{E}$ mark the diffraction peaks that can still be identified after the test. 


\section{Reference}

(1) McCrory, C. C. L.; Jung, S.; Peters, J. C.; Jaramillo, T. F. Benchmarking Heterogeneous Electrocatalysts for the Oxygen Evolution Reaction J. Am. Chem. Soc. 2013, 135, 16977-16987.

(2) Wang, J.; Zhong, H.; Qin, Y.; Zhang, X. An Efficient Three-Dimensional Oxygen Evolution Electrode Angew. Chem. Int. Ed. 2013, 52, 5248-5253.

(3) Chen, S.; Duan, J.; Ran, J.; Jaroniec, M.; Qiao, S. Z. N-doped Graphene Film-confined Nickel Nanoparticles as A Highly Efficient Three-dimensional Oxygen Evolution Electrocatalyst Energy Environ. Sci. 2013, 6, 3693-3699.

(4) Zhou, W.; Wu, X.-J.; Cao, X.; Huang, X.; Tan, C.; Tian, J.; Liu, H.; Wang, J.; Zhang, H. Ni3S2 Nanorods/Ni Foam Composite Electrode with Low Overpotential for Electrocatalytic Oxygen Evolution Energy Environ. Sci. 2013, 6, 2921-2924.

(5) Liu, Q.; Jin, J.; Zhang, J. NiCo2S4@graphene as a Bifunctional Electrocatalyst for Oxygen Reduction and Evolution Reactions ACS Appl. Mater. Interfaces 2013, 5, 5002-5008.

(6) Chen, S.; Duan, J.; Jaroniec, M.; Qiao, S. Z. Three-Dimensional N-Doped Graphene Hydrogel/NiCo Double Hydroxide Electrocatalysts for Highly Efficient Oxygen Evolution Angew. Chem. Int. Ed. 2013, 52, 13567-13570.

(7) Louie, M. W.; Bell, A. T. An Investigation of Thin-Film Ni-Fe Oxide Catalysts for the Electrochemical Evolution of Oxygen J. Am. Chem. Soc. 2013, 135, 12329-12337.

(8) Corrigan, D. A.; Bendert, R. M. Effect of Coprecipitated Metal Ions on the Electrochemistry of Nickel Hydroxide Thin Films: Cyclic Voltammetry in $1 \mathrm{M} \mathrm{KOH} \mathrm{J.} \mathrm{Electrochem.} \mathrm{Soc.} \mathrm{1989,} \mathrm{136,}$ 723-728.

(9) Corrigan, D. A. The Catalysis of the Oxygen Evolution Reaction by Iron Impurities in Thin Film Nickel Oxide Electrodes J. Electrochem. Soc. 1987, 134, 377-384.

(10) Lee, D. U.; Kim, B. J.; Chen, Z. One-pot Synthesis of a Mesoporous NiCo2O4 Nanoplatelet and Graphene Hybrid and Its Oxygen Reduction and Evolution Activities as An Efficient Bi-functional Electrocatalyst J. Mater. Chem. A 2013, 1, 4754-4762.

(11) Li, X.; Walsh, F. C.; Pletcher, D. Nickel Based Electrocatalysts for Oxygen Evolution in High Current Density, Alkaline Water Electrolysers Phys. Chem. Chem. Phys. 2011, 13, 1162-1167.

(12) Xiao, Q.; Zhang, Y.; Guo, X.; Jing, L.; Yang, Z.; Xue, Y.; Yan, Y.-M.; Sun, K. A Highperformance Electrocatalyst for Oxygen Evolution Reactions Based on Electrochemical Posttreatment of Ultrathin Carbon Layer Coated Cobalt Nanoparticles Chem. Comm. 2014, 50, 1301913022.

(13) Zhan, Y.; Xu, C.; Lu, M.; Liu, Z.; Lee, J. Y. Mn and Co Co-substituted Fe3O4 Nanoparticles on Nitrogen-doped Reduced Graphene Oxide for Oxygen Electrocatalysis in Alkaline Solution J. Mater. Chem. A 2014, 2, 16217-16223. 